\title{
Corrigendum to "Fall Risk Reduction Program Paired with a Transportation Program in an Underserved, Urban Minority Community: A Qualitative Evaluation"
}

\author{
Thelma J. Mielenz ${ }^{1},{ }^{1}$ Laura Durbin, ${ }^{1}$ Fern Hertzberg, ${ }^{2}$ \\ Diana Noble-Hernandez, ${ }^{2}$ and Julie A. Sorensen (iD ${ }^{3}$ \\ ${ }^{1}$ Mailman School of Public Health, Columbia University, 722 West 168th Street, New York, NY 10032, USA \\ ${ }^{2}$ ARC XVI Fort Washington Inc. (ARC), 4111 Broadway, New York, NY 10033, USA \\ ${ }^{3}$ Bassett Research Institute, One Atwell Rd., Cooperstown, NY 13326, USA
}

Correspondence should be addressed to Julie A. Sorensen; julie.sorensen@bassett.org

Received 1 October 2020; Accepted 1 October 2020; Published 16 October 2020

Copyright (C 2020 Thelma J. Mielenz et al. This is an open access article distributed under the Creative Commons Attribution License, which permits unrestricted use, distribution, and reproduction in any medium, provided the original work is properly cited.

In the article titled "Fall Risk Reduction Program Paired with a Transportation Program in an Underserved, Urban Minority Community: A Qualitative Evaluation" [1], the Acknowledgements section was omitted from the article in error. The acknowledgements section should read as follows:

"This research is supported by Grant 1 R49 CE002096-01 from the National Center for Injury Prevention and Control, Centers for Disease Control and Prevention to the Center for Injury Epidemiology and Prevention at Columbia University. Its contents are solely the responsibility of the authors and do not necessarily represent the official views of the Centers for Disease Control and Prevention. We dedicate this manuscript to Diana Noble-Hernandez for her tireless efforts in supporting older adults in their communities across Upper Manhattan."

\section{References}

[1] T. J. Mielenz, L. Durbin, F. Hertzberg, D. Noble-Hernandez, and J. A. Sorensen, "Fall Risk reduction Program paired with a transportation Program in an underserved, urban minority community: a qualitative evaluation," Journal of Aging Research, vol. 2019, Article ID 2719290, 8 pages, 2019. 